\title{
The Quadriplegia Index of Function (QIF): Sensitivity and Reliability Demonstrated in a Study of Thirty Quadriplegic Patients
}

Glen E. Gresham, M.D.; Maria L. C. Labi, Ph.D.; Sharon S. Dittmar, R.N., Ph.D.; John T. Hicks, R.P.T.; Sandra Z. Joyce, O.T.R.; and Margaret A. Phillips Stehlik, R.N., M.S.

Erie County Medical Centre and State University of New York at Buffalo, Buffalo, New York 14215

\section{Summary}

The Quadriplegia Index of Function (QIF) was originally developed by the authors in 1980 because the popular Barthel Index was deemed too insensitive to document the small but significant functional gains made by quadriplegics (tetraplegics) during medical rehabilitation. The QIF has now been tested on a group of 30 complete quadriplegic patients at admission to and discharge from inpatient medical rehabilitation. Resultant scores were compared to those simultaneously obtained by the Barthel Index and the Kenny Self-Care Evaluation. The $Q I F$ was found to be more sensitive (46 per cent improvement as opposed to 30 per cent by the Kenny Self Care Evaluation and 20 per cent by the Barthel Index). The QIF was also tested for reliability. Ratings by three different nurses, working independently, were found to be significantly positively correlated for all sub-scores $(p<\cdot 001)$. We conclude that the QIF provides a useful option in choosing a functional assessment instrument for use with quadriplegic patients.

Key words: Quadriplegia (Tetraplegia); Spinal cord injuries; Activities of daily living; Rehabilitation; Disability evaluation.

\section{Introduction}

In 1979, Granger, Albrecht and Hamilton (Granger, et al., 1979) showed that the Barthel Index (Mahoney and Barthel, 1965) could document functional gains in Activities of Daily Living (ADL) made during medical rehabilitation by an otherwise undifferentiated group of 95 spinal cord injury (SCI) patients. Others

Presented in part at the 57th and 58th Annual Sessions of the American Congress of Rehabilitation Medicine, Washington, D.C., October, 1980, and San Diego, November, 1981, and at the 8th Annual Session of the American Spinal Injury Association, New York, April 1982.

Address reprint requests to: Glen E. Gresham, M.D., Department of Rehabilitation Medicine, State University of New York at Buffalo, 462 Grider Street, Buffalo, New York 14215. 
(DeVivo and Fine, 1982; Young and McCutcheon, 1978) have also selected the Barthel Index as a means of classifying ADL status in SCI.

Our experience has been that the Barthel Index does, indeed, work satisfactorily for paraplegia (Gresham, et al., 1980). Quadriplegics, however, often make small but significant functional gains during rehabilitation that are not reflected by significantly improved Barthel Index scores. For this reason, we developed a new Quadriplegia Index of Function (QIF) which we believed would be more sensitive and comprehensive (Gresham, et al., 1980; Labi, et al., 1981). We now are able to report the results of using the QIF to document changes in functional status in a group of 30 patients with quadriplegia (tetraplegia).

\section{Methods}

The Quadriplegia Index of Function (QIF) is comprised of 10 variables (transfers, grooming, bathing, feeding, dressing, wheelchair mobility, bed activities, bladder programme bowel programme and understanding of personal care). The component activities and relative weights of each of these variables are shown in Table 1. Scoring criteria are highly specific. A final score is derived, ranging from

Table 1 Component Activity Categories and Relative Weights of Each in the Quadriplegia Index of Function (QIF)

\begin{tabular}{|c|c|c|}
\hline Category & $\begin{array}{l}\text { Component Activities } \\
\text { (Each scored separately) }\end{array}$ & $\begin{array}{l}\text { Relative Weights } \\
\text { of Category } \\
\text { (per cent) }\end{array}$ \\
\hline I. Transfers & $\begin{array}{l}\text { 1. Bed-Chair } \\
\text { 2. Chair-Bed } \\
\text { 3. Chair-Toilet/Commode } \\
\text { 4. Toilet/Commode-Chair } \\
\text { 5. Chair-Vehicle } \\
\text { 6. Vehicle-Chair } \\
\text { 7. Chair-Shower/Tub } \\
\text { 8. Shower/Tub-Chair }\end{array}$ & 8 \\
\hline II. Grooming & $\begin{array}{l}\text { 1. Brushing teeth/managing } \\
\text { dentures } \\
\text { 2. Brushing/Combing hair } \\
\text { 3. Shaving (men) } \\
\text { 4. Managing tampon (women) }\end{array}$ & 6 \\
\hline III. Bathing & $\begin{array}{l}\text { 1. Wash/Dry upper body } \\
\text { 2. Wash/Dry lower body } \\
\text { 3. Wash/Dry feet } \\
\text { 4. Wash/Dry hair }\end{array}$ & 4 \\
\hline IV. Feeding & $\begin{array}{l}\text { 1. Drink from cup/glass } \\
\text { 2. Use spoon/fork } \\
\text { 3. Cut food (meat) } \\
\text { 4. Pour liquids out } \\
\text { 5. Open carton/jar } \\
\text { 6. Apply spreads to bread } \\
\text { 7. Prepare simple meals } \\
\text { 8. Apply adaptive equipment }\end{array}$ & 12 \\
\hline V. Dressing & $\begin{array}{l}\text { 1. Upper indoor clothes } \\
\text { on/off } \\
\text { 2. Lower indoor clothes } \\
\text { on/off }\end{array}$ & 10 \\
\hline
\end{tabular}


VI. Wheelchair Mobility

VII. Bed Activities

IX. Bowel Programme
3. Upper outdoor (heavy) clothes on/off

4. Socks on/off

5. Shoes on/off

6. Fasteners

1. Turn corners

2. Reverse direction

3. Lock wheelchair brakes

4. Propel wheelchair on rough/ uneven surface

5. Propel wheelchair on an incline

6. Move and position in chair

7. Maintain sitting balance

1. Supine-prone

2. Supine to long sitting

3. Supine-side

4. Side-Side

5. Maintain long sitting balance

Separate sets of scoring criteria for:
A. Voluntary voiding
1. Toilet
2. Commode
B. Intermittent catheteriza- tion programme
C. Autonomic bladder programme
D. Indwelling catheter
E. Ileal diversion
F. Crédé

Separate sets of scoring criteria for:

A. Complete control
1. Toilet
2. Commode

B. Suppository

1. Toilet

2. Commode/Bed/Chux pad

C. Digital disimpaction

1. Toilet disimpaction

2. Commode/Bed disimpaction

D. Digital or mechanical stimulation
1. Toilet
2. Commode/Bed

$\mathrm{X}$. Understanding personal care

1. Skin care

3. Medications

4. Equipment

5. Range of motion

6. Autonomic dysreflexia

7. Upper respiratory infection

8. Urinary tract infection

9. Deep vein thrombosis

10. Obtaining human services 


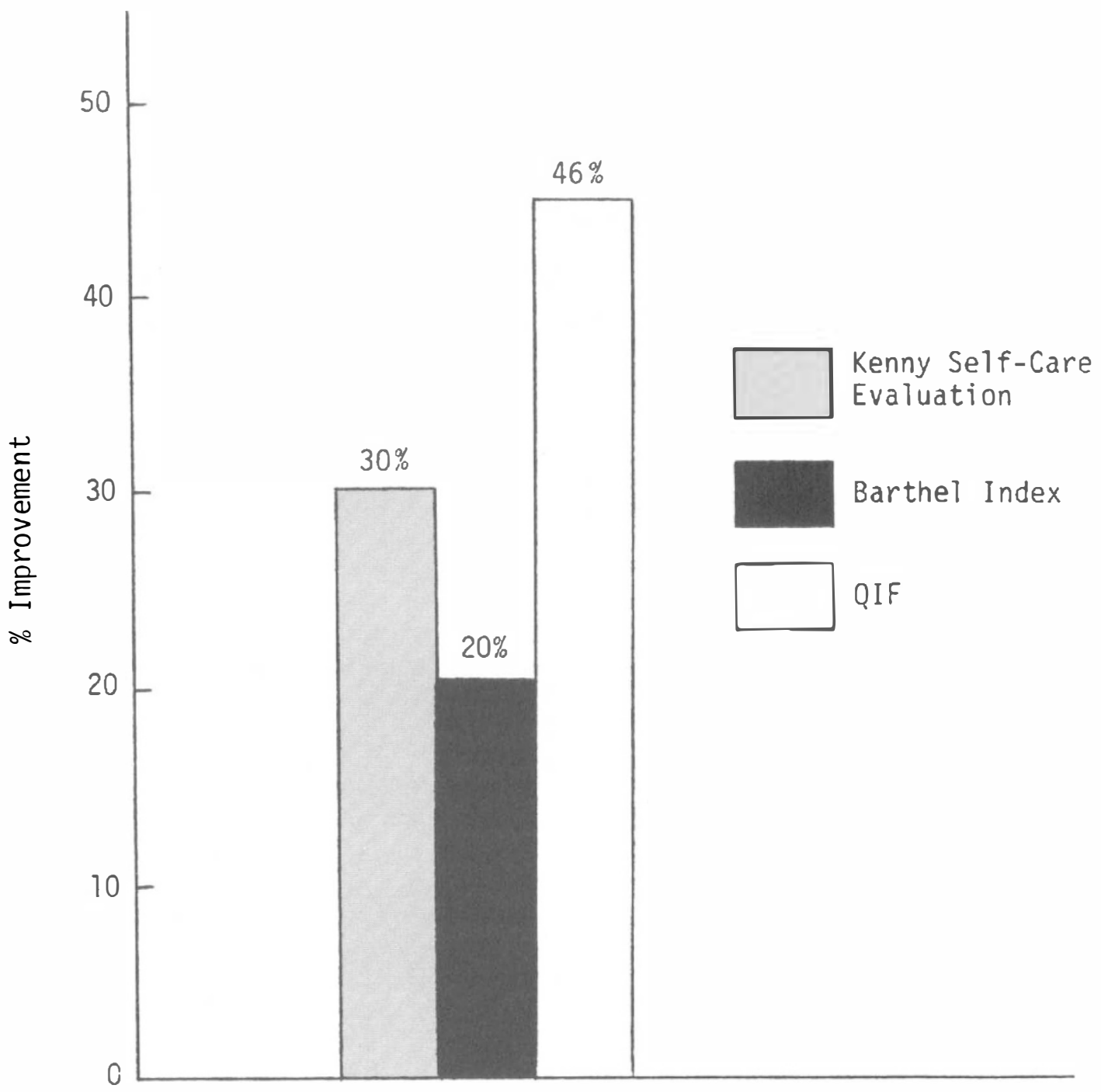

Figure 1. Average Per cent Improvement of Thirty Quadriplegics on the Kenny Self-Care Evaluation, Barthel Index, and QIF.

0 to 100 , but subscores for each variable are available if needed. Copies of the QIF, including scoring instructions, are available from the authors.

Thirty quadriplegic patients (all with complete lesion ranging from $\mathrm{C} 4$ to $\mathrm{C} 8$ ) from the Erie County Medical Centre, Buffalo, and Strong Memorial Hospital, Rochester, were classified by the QIF at admission to and discharge from medical rehabilitation. These ratings were compared with simultaneously derived scores (which can be obtained by use of the Donaldson ADL Evaluation Form [Donaldson, et al., 1973]) by the Barthel Index (Mahoney and Barthel, 1965) and the Kenny Self-Care Evaluation (Schoening et al., 1968). In addition, 20 of the patients were independently evaluated, using the QIF, by three different raters 
(all nurses). The scores obtained by the three different observers were subsequently correlated, using Pearson's $r$, and tested for statistical significance.

\section{Results}

Individual assessments were all completed in less than one half hour by rehabilitation nurses familiar with the instrument. No problems in clarity of classification criteria or scoring instructions were encountered. Patient cooperation was good. As shown in Fig. 1, the average per cent of improvement in QIF scores, between admission and discharge was 46 per cent (mean QIF score on admission was 3.9 , rising to a mean score of 49.5 on discharge). In contrast, the average per cent of improvement was 30 per cent by the Kenny Self-Care Evaluation and 20 per cent by the Barthel Index.

The Pearson's Coefficient of Correlation value $\left(r^{2}\right)$, for the ratings by three different observers on 20 patients, are shown for each component in Table 2 . As noted, all $\mathrm{r}^{2}$ values were statistically significant at the level of $\mathrm{p}<\cdot 001$.

\section{Conclusions}

As with any new functional assessment instrument, the merits of the QIF had to be determined in the areas of validity, feasibility, acceptability, sensitivity and reliability.

Validity is usually assessed subjectively, by inference, where no pre-existing 'gold standard' is available. For the QIF, good face validity was suggested by the fact that it was originally developed by an experienced multidisciplinary SCI team. In addition, other knowledgeable observers using the instrument have deemed it appropriate and comprehensive. Construct validity is established by the fact that the QIF includes all of the basic variables found in the Barthel Index (Mahoney and Barthel, 1965) and the Kenny Self-Care Evaluation (Schoening, et al., 1968). The feasibility of the QIF was demonstrated by its requiring one half hour or less to administer (by rehabilitation nurses familiar with the instrument). Good patient cooperation and lack of expressed concerns by the various raters suggested adequate acceptability.

Table 2 Pearson's Coefficient of Correlation $\left(\mathbf{r}^{2}\right)$ on QIF's Categories in a Study of Interrater Reliability (Three Observers; 20 Complete Quadriplegic Patients)

\begin{tabular}{llll}
\hline $\begin{array}{l}\text { QIF Component } \\
\text { Variables }\end{array}$ & R1/R2 & R2/R3 & R1/R3 \\
\hline Transfer & $\cdot 75$ & .91 & .62 \\
Grooming & .83 & .67 & .64 \\
Bathing & .87 & .90 & .83 \\
Feeding & .74 & .92 & .67 \\
Bed Activities & .84 & .67 & .55 \\
Wheelchair Mobility & .86 & .67 & .66 \\
Dressing & .95 & .86 & .66 \\
Bowel Programme & .82 & .95 & .68 \\
Bladder Programme & .68 & .72 & .91 \\
\hline
\end{tabular}

All $\mathrm{r}^{2}$ values are statistically significant $(\mathrm{p}<\cdot 001)$. 
The sensitivity of the QIF was of particular interest since this had been the major reason for its creation. As shown in Fig. 1, the QIF is clearly more sensitive, in documenting functional improvements in quadriplegics, than either the Kenny Self-Care Evaluation (Schoening, et al., 1968) or the Barthel Index (Mahoney and Barthel, 1965).

Finally, significant interrater reliability in the use of the QIF was demonstrated. Significant correlations between the three independent ratings were documented for all subscores.

The above findings suggest that the QIF can be used with confidence by those who wish to provide this type and degree of documentation of functional status and its changes in patients with quadriplegia, either for clinical research or programme monitoring purposes.

\section{Acknowledgements}

The authors are indebted to Charles J. Gibson, M.D., Strong Memorial Hospital and the University of Rochester, and to his associates for their help and encouragement.

\section{Résumé}

A l'origine, the Quadriplegia Index of Function (QIF) (l'Index du Fonctionnement de la tétraplégie) était concu et développé par les auteurs (en 1980) pour la raison que l'Index Barthel, quoique populaire, était jugé trop insensible en ce qui concerne l'enregistrement des progrès minimes mais significatifs réalisés par des malades tétraplégiques au cours de la réhabilitation médicale. On a maintenant mis le QIF a l'épreuve avec un groupe de 30 malades entièrement tétraplégiques qui ont été contrôlés en entrant et en sortant du programme médical de réhabilitation à l'hôspital. Les résultats de ce contrôle ont été comparés à ceux qui ont été obtenus simultanément par l'Index Barthel et par le Kenny Self-Care Evaluation. Le QIF s'est avéré être plus sensible que ceux-ci (une amélioration de 46 purcent a été enregistrée comparé à 30 pourcent en ce qui concerne le Kenny Self-Care Evaluation et 20 pourcent pour l'Index Barthel). Le QIF a été également contrôlé en ce qui concerne la sécurité du fonctionnement. Des évaluations faites indépendemment par trois infirmières differéntes ont montré une corrélation positive et significative pour tout résultats en toutes catégories. Nous concluons que le QIF se présente comme une option utile au moment de choisir un instrument pour mesurer le niveau de fonctionnement des malades tétraplégiques.

\section{Zusammenfassung}

Die Quadriplegia (Tetraplegie) Index (Zeiger) der Funktion (sstörung) (QIF) war ursprünglich durch Untersuchung der Forschern dieser Schrift in Jahr 1980 entwickelt.

Da sie der meinung waren dass der populäre Barthel Index zu unempfindlich als Beweisstück für die kleinen aber bedeutungs vollen Verstärkungen die, die Patienten mit Quadriplegia durch ärztlicher Rehabilitierung gemacht hatten.

Die QIF wurde nun an einer Gruppe von 30 vollständigen Quadriplegia Patientan geprüft, von Aufrahme (intake) zu Erfüllung der ärztlicher Rehabilitierung. Die resultierende Ergebnisse waren gleichzeitig miteinander vergleicht-mit Dem Barthel Index and Der Kenny Selbsterhaltungs (Self-Care) bestimmung (Evaluation).

Es wurde fest gestellt dass die QIF viel mehr empfindlich war (46 Prozent Verbesserung gegen 30 Prozent der Kenny Selbsterhaltungs bestimmung und 20 Prozent von dem Barthel Index).

Die QIF wurde auch geprüft für Zuverlässigkeit. Drei verschiedene Krankenschwestern, in unabhängiger Arbeit, hatten sie (QIF) gemessen und die Auskumft fand sich bedeutungs voll und unzweifelhalft und gegenseitig Abhängig (correlated) für alle Unterabteilige Punktzahlen (subscores) $(\mathrm{p}<001)$.

Wir beschliessen dann dass QIF uns eine nützliche Möglichkeit zur Verfügung in der Auswahl/ eines dienstlichen Bestimmungs Werkzeug zum Gebrauch stellt, als Messgerät für die Patienten die Quadriplegia haben. 


\section{References}

Devivo MJ, FINE PR 1982 Employment status of spinal cord injured patients 3 years after injury. Archives of Physical Medicine and Rehabilitation 63:200-203

Donaldson SW, WAGNER C, Gresham GE 1973 A unified ADL evaluation form. Archives of Physical Medicine and Rehabilitation 54:175-179

Granger CV, Albrecht GL, Hamilton BB 1979 Outcome of comprehensive medical rehabilitation: Measurement by PULSES profile and the Barthel index. Archives of Physical Medicine and Rehabilitation 60:145-154

Gresham GE, LABI ML, DitTmaR SS, et al. 1980 Quadriplegia index of function (Abstract). Archives of Physical Medicine and Rehabilitation 61:493

LABI ML, Dittmar SS, Hicks JT, et al. 1981 Quadriplegia index of function: One-year followup (Abstract). Archives of Physical Medicine and Rehabilitation 62:532-533

MAHONEY FI, BARThel DW 1965 Functional evaluation: The Barthel index. Maryland State Medical Journal 14:61-65

SchoENING HA, IvERSEN IA 1968 Numerical scoring of self-care status: A study of the Kenny self-care evaluation. Archives of Physical Medicine and Rehabilitation 49:221-229

Young JS (ed.), McCutchen RL (Assoc. Ed.) 1978 Proceedings, National Spinal Cord Injury Model Systems' Conference. Appendix 1: Initial SCI hospitalization and rehabilitation variable summary, pp. 13-14; Appendix 2: Annual evaluation variable summary, pp. 15-16; National Spinal Cord Injury Data Research Center: Phoenix 